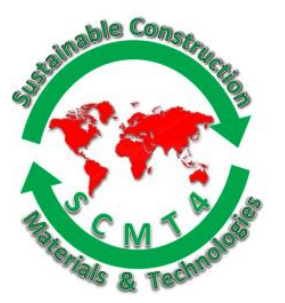

SCMT4

Las Vegas, USA, August 7-11, 2016

\title{
Pore Structure Analysis of Mortar Under Freeze-Thaw Cycles Using X-Ray Computed Tomography
}

\author{
Katsufumi Hashimoto ${ }^{1 \mathrm{a}}$, Hiroshi Yokota ${ }^{\text {bb }}$, and Takafumi Sugiyama ${ }^{\text {1c }}$ \\ ${ }^{1}$ Faculty of Engineering, Hokkaido University, Kita 13, Nishi 8, Kita-Ku, Sapporo, Hokkaido 060-8628, \\ Japan. ${ }^{1 a}$ Email: <hashimoto/k@eng.hokudai.ac.jp>, ${ }^{1 b}$ Email: <yokota@eng.hokudai.ac.jp>,

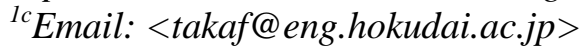

\begin{abstract}
Frost damage due to freeze thaw action of pore water in concrete is an important issue on durability of concrete structures in cold regions. It is generally known that different temperature histories in freezethaw cycles affect scaling of concrete, in which the pore structure might be changed due to propagation of micro cracks. In previous research, 3D images from X-ray computed tomography have been used to analyze the pore structure of concrete. This study aimed to evaluate the pore structure of mortar under freeze-thaw cycles with different temperature histories by using X-ray computed tomography, evaluating and detecting the alteration of pore structure and discuss their influences on permeability degradation. As the results, 1) the temperature histories gave different progress of residual strain and void distributions alteration, in which decrease behavior of tortuosity and spacing factor were able to be explained using residual strain due to frost damage; 2) propagation of micro cracks due to frost damage probably increased spacing factors and tortuosity calculated from information obtained in the analysis using X-ray computed tomography; and 3) tortuosity and spacing factor linearly correlated with diffusion coefficient although void ratio did not correlated with diffusion coefficient.
\end{abstract}

\section{INTRODUCTION}

In cold regions and snowy districts, frost damage of concrete is one of the serious deterioration, and the influence of freezing and thawing action on structural performance degradation has been reported by many researchers. It is considered that pressure derived from freezing and thawing of water in the concrete causes micro cracks, pop-out, and/or scaling on the concrete surface. However, deterioration mechanism and performance degradation of concrete after freeze-thaw cycles are still unclear. Understanding the frost damage mechanism with alteration of pore structure, the deterioration, such as propagation of micro cracks, can be clarified.

Previous studies have reported that the heating or cooling rate in a freeze-thaw cycles and the highest or lowest temperature retention time in the cycles affect the amount of surface scaling and strain of concrete [Bishnoi 2008; Tsukinaga et al. 1997]. Therefore, it is supposed that temperature history of freeze-thaw cycles changes the mechanical properties of concrete. Especially, the effect of temperature history on tensile properties of mortar has been investigated [Jacobsen and Sellevold 1997]. In the results, 
temperature history influenced on strain increasing rate, also freezing and thawing times and rates affected the progress of frost damage.

It is very important to understand mass penetration, such as moisture and chloride ion accelerating frost damage [Mu et al. 2002; Promentilla et al. 2008] in the concrete, which leads deterioration due to frost damage. Cement hardened matrix possibly forms various pore structures while degradation with having different temperature histories in the aforementioned phenomena. As the results, the change in the degradation mechanism of frost damage potentially affects the permeability characteristics such as a chloride ion diffusion coefficient under frost damage environment.

As for evaluating geometrical information on pore structure of deteriorated cementitious materials, the authors observed the three-dimensional structure of air bubbles and voids using X-ray Computed Tomography (CT) images and aimed to understand the internal structure of the hardened cement paste by image analysis calculating porosity and diffusion tortuosity [Promentilla et al. 2009; Hashimoto et al. 2013]. Degradation mechanism due to frost damage and chloride ion diffusion coefficient subjected to frost damage environments is evaluated in this paper, using a 3D stereoscopic image by X-ray CT and pore structure analysis by MIP (mercury intrusion porosimeter) from the viewpoint of investigation on pore structure and connectivity.

\section{EXPERIMENTAL PROCEDURE}

Specimens. In this study, ordinary Portland cement (OPC, density: $3.16 \mathrm{~g} / \mathrm{cm}^{3}$ and specific surface: 3320 $\mathrm{cm}^{2} / \mathrm{g}$ ) and quartz sand (saturated surface dry density: $2.67 \mathrm{~g} / \mathrm{m}^{3}$, fineness modulus: 2.82 , and maximum size: $1.7 \mathrm{~mm}$ ) were used, and mortar specimens were prepared with $\mathrm{W} / \mathrm{C}=0.5$. Distilled water was used for mixing water. Air entraining agent was not used. The specimens were demolded after 24 hours from casting and cured by immersion in $20^{\circ} \mathrm{C}$ water for 28 days. After the curing, $30 \mathrm{~mm}$ x $70 \mathrm{~mm}$ x $5 \mathrm{~mm}$ disc samples from the $40 \mathrm{~mm} \times 40 \mathrm{~mm} \times 160 \mathrm{~mm}$ original prism, where it seems to have less bleeding effects in the body, were cut and taken out with using micro saw [Hashimoto et al. 2010; Hisada et al. 2003]. The samples were dipped into a large volume of acetone at $20^{\circ} \mathrm{C}$ for 30 minutes under reduced pressure $\left(20^{\circ} \mathrm{C}, 2.33 \mathrm{kPa}\right)$, in order to terminate the hydration reaction.

Freeze-thaw cycles. Freeze-thaw cycles (abbreviated as FTC) in this study are shown in Figure 1 based on the RILEM-CDF method. Though 1 cycle takes 12 hours in the original RILEM CDF method, 4 patterns of the freeze-thaw cycles, RILEM 12-hour (R12), RILEM 6-hour (R6), RILEM 4-hour (R4) and RILEM 2-hour (R2) are arranged for acceleration of frost damage in shorter periods. Freeze-thaw cycles were continued until 10 cycles in all the patterns. De-ionized water was fully absorbed in the test piece before starting FTC and after finishing every 5 cycles. Strain was measured during FTC with compensating temperature strain by using the strain of a quartz sample. To measure strain of the test piece, two strain gages were glued on its opposite surfaces. The test pieces without FTC were also prepared (abbreviated as NonFTC) for reference.

Air void distribution. As for air void distribution in cement hardened matrix [Promentilla et al. 2008], $\mathrm{X}$-ray computed tomography constructs three-dimensional 3D digital image from a series of twodimensional (2D) sliced images from a $5 \mathrm{~mm}$ x $5 \mathrm{~mm}$ x $30 \mathrm{~mm}$ mortar prism, which comes out from the middle of the aforementioned samples before and after FTC, and each slice was 1024 by 1024 pixels in size, with each pixel measuring $8.5 \mu \mathrm{m}$ by $8.5 \mu \mathrm{m}$ in this study. Figure 2 shows an example of 3-D X-ray CT scanning image.

The focused 500 pixels x 500 pixels area for data acquisition was composed in the specimen and 355 slices were obtained for a volume of interest (VOI). Stacking up of binary (black and white) images after pore segmentation of the VOI to identify the pore and solid voxels (volume elements) respectively. As the 


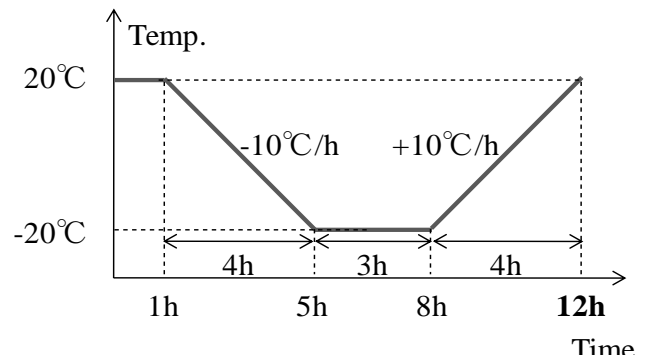

a) RILEM 12-hour (R12)

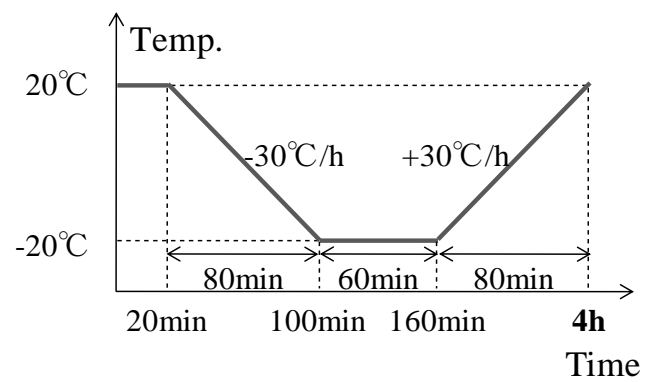

c) RILEM 4-hour (R4)

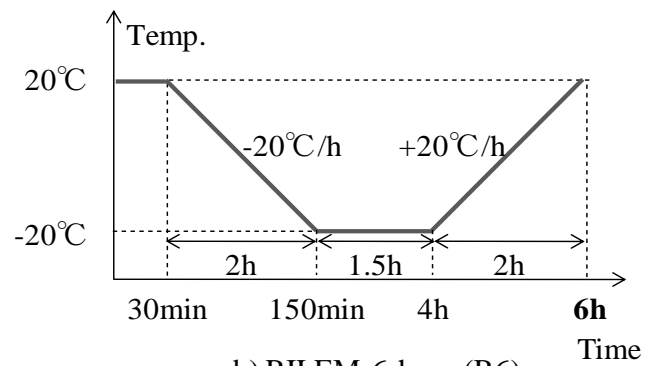

b) RILEM 6-hour (R6)

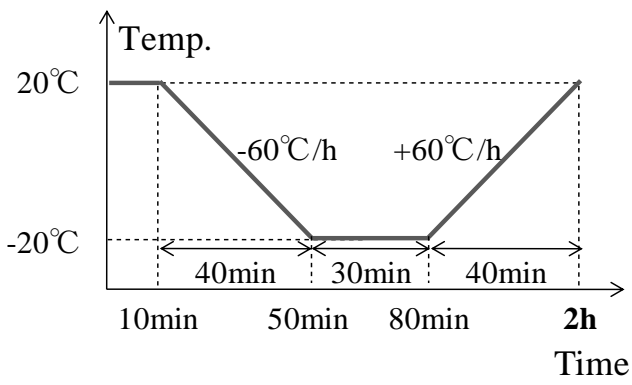

d) RILEM 2-hour (R2)

Figure 1. Freeze-thaw cycles
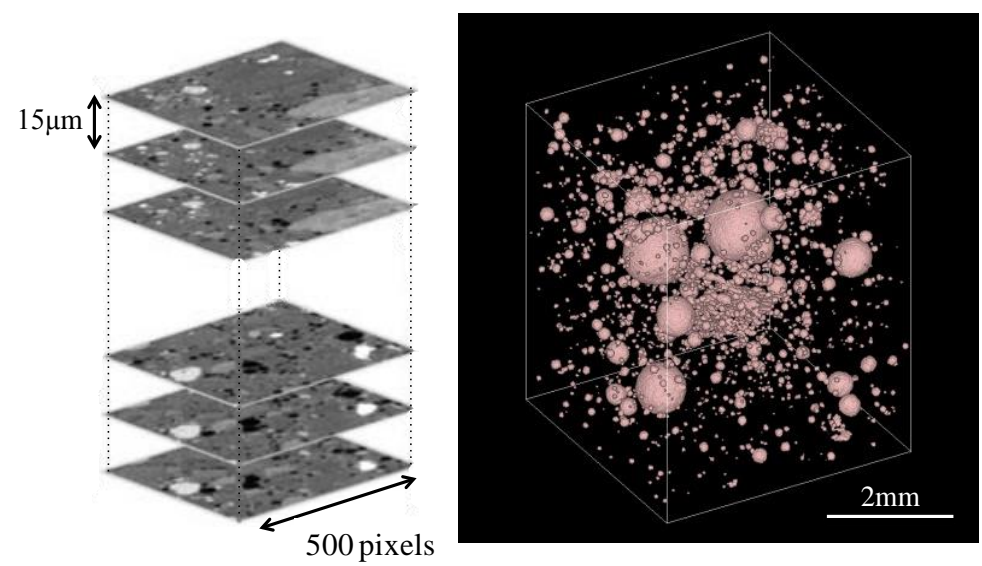

Figure 2. An example of 3D X-ray CT scanning image

results of this analysis, the minimum void diameter is $10 \mu \mathrm{m}$, and voids that consist of $10 \mu \mathrm{m}$ sized cube on a side in hardened body are detected rather than the physical characteristics of space and less than 10 $\mu \mathrm{m}$ porosity and cracks.

Random walk simulation (RWS) to qualify spacing factor and tortuosity. Using 3D X-ray CT scanning images, random walk simulation was applied to calculate the spacing factor and tortuosity [Nakashima et al. 2007; Stauffer and Aharony 1994]. The random walk simulation is an algorithm in which a imaginary walker, as mass transfer through voids in the lattice shaped coordinates, moves with randomly changing the direction. Diffusion tortuosity is introduced in this study as a pore structuretransport geometrical parameter given from 3D-microgeometry of air voids in cement hardened matrix [Promentilla et al. 2008; Promentilla et al. 2009]. Diffusion tortuosity can be calculated as the ratio of the 
self-diffusion coefficient of the random walkers in free space to a long term self-diffusion coefficient. The time-dependent self-diffusion coefficient in 3D lattice space comes from Equation 1 [Nakashima et al. 2007].

$$
D\left(t_{D}\right)=\frac{1}{6} \frac{d\left\langle r^{2}\right\rangle}{d t_{D}}
$$

where $\left\langle r^{2}\right\rangle$ and $t_{D}$ refer to the mean square displacement of the walkers and dimensionless lattice walk time respectively.

Also, $r^{2}$ in Equation 1, which is the mean square displacement of the walkers in a simple cubic lattice model, is calculated with Equation 2.

$$
\left\langle r\left(t_{D}\right)^{2}\right\rangle=\frac{1}{n} \sum_{j=1}^{n} \sum_{i=1}^{3}\left\{x_{i}^{j}\left(t_{D}\right)-x_{i}^{j}(0)\right\}^{2}
$$

where $n$ is the number of walkers, and $x, y$ and $z$ are the 3D coordinates of the $i$-th walker's position at time $t_{D}$.

Accordingly, diffusion tortuosity $\tau$ is described in Equation 3 showing the ratio of self-diffusion coefficient $D_{0}$ in a $100 \%$ free space to self-diffusion coefficient $D$ in a porous media such as cement hardened matrix.

$$
\tau=\frac{D_{0}}{D}
$$

In this study, 100,000 walkers were loaded in the random walker simulation. As mentioned above, tortuosity is explained as the ratio of self-diffusion coefficient in a $100 \%$ free space to a self-diffusion coefficient, it is said that the pore structure has higher connectivity when tortuosity get closer to 1 . Assuming that equable air voids are distributed in VOI, equable void radius $r$ is calculated in Equation 4 with dividing the total of all pore voxels with the number of pores. Additionally applying Equation 5 for calculating the surface area $\alpha$, the pore spacing factor is given from Equation 6 [Ohta et al. 1986].

$$
\begin{aligned}
r & =\sqrt[3]{\frac{3 V}{4 \pi}} \\
& =\frac{4 r^{2}}{\frac{4}{3} r^{3}}=\frac{3}{r} \\
L & =\frac{3}{-1.4} \sqrt[3]{\frac{P}{A}+1} 1
\end{aligned}
$$

Where $r$ is the equable void radius $(\mu \mathrm{m}), V$ is the connected void volume $\left(\mu \mathrm{m}^{3}\right), \alpha$ is the surface area $\left(\mu \mathrm{m}^{2}\right), L$ is the spacing factor $(\mu \mathrm{m}), P$ is volume ratio of cement paste in mortar, and $A$ is the volume ratio of air voids in mortar. 

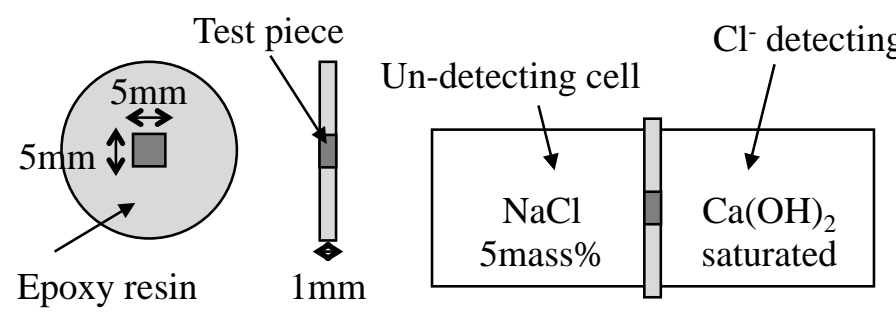

Figure 3. Minute diffusion test

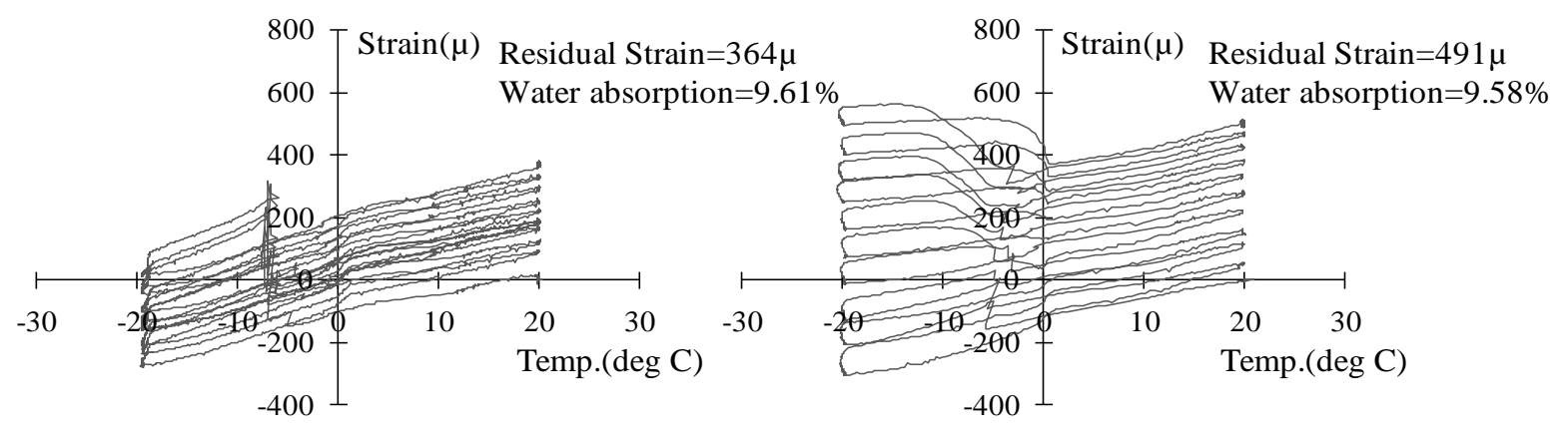

a) RILEM 12-hour (R12)

b) RILEM 6-hour(R6)

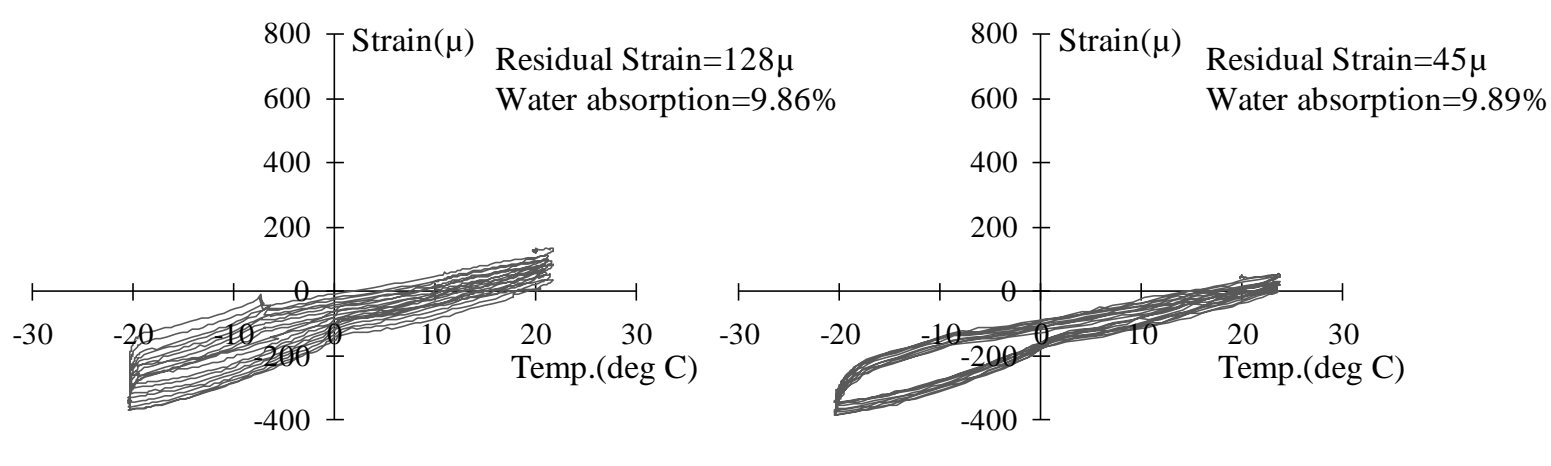

c) RILEM 4-hour (R4)

d) RILEM 2-hour (R2)

Figure 4. Temperature-strain curve during FTC

Measurement of effective diffusion coefficient. The diffusion coefficient was measured by a minute diffusion test as shown in Figure 3 [Otsuki et al. 2004] for a test piece produced from the middle of disc sample before and after FTC. When the increase of chloride ion concentration in the detecting cell becomes constant, the rate was defined as the increase speed of chloride ion concentration. The diffusion coefficient was calculated with Fick's law on the increased speed of chloride ion concentration and ion flux per unit time and area as shown in Equation 7. As mentioned above, very fine sand $(<1.7 \mathrm{~mm})$ was used in this study to avoid the possibility of the samples forming ITZ (Interfacial Transition Zone between aggregate and cement paste) which might affect the results. 


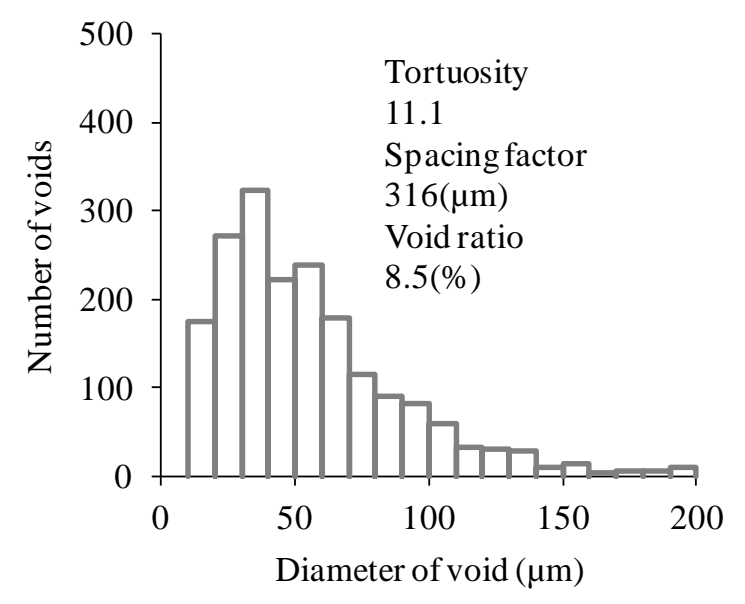

Figure 5. Air void distribution (NonFTC)

$$
F=-D_{e} \frac{\Delta C}{\Delta x}=Q_{C l} \cdot \frac{V_{C e l l}}{A^{\prime}}
$$

Where $F$ is the chloride ion flux ( $\mathrm{mol} / \mathrm{cm}^{2} /$ year), $D_{e}$ is the effective diffusion coefficient $\left(\mathrm{cm}^{2} /\right.$ year), $\Delta C$ is the differential concentration $\left(\mathrm{mol} / \mathrm{cm}^{3}\right), \Delta x$ is the thickness of test piece $(\mathrm{cm}), Q_{C l}$ is the permeability rate of chloride ion $\left(\mathrm{mol} / \mathrm{cm}^{3} / \mathrm{sec}\right), V_{\text {Cell }}$ is the volume of a cell $\left(\mathrm{cm}^{3}\right)$, and $A^{\prime}$ is the cross-sectional area of test piece $\left(\mathrm{cm}^{2}\right)$.

\section{RESULTS AND DISCUSSIONS}

Residual strain in freeze-thaw cycles. Temperature-strain curves during FTC are shown in Figure 4. The temperature was measured on the opposite surfaces of test piece with thermocouples.

It was confirmed that the temperature history of FTC greatly influences on increase in strain which implicitly indicates that frost damage progresses according to the temperature history. Residual strains, which is defined as the dilation strain at $20{ }^{\circ} \mathrm{C}$ after the FTC test were $491 \mu$ (R6), 364 $\mu$ (R12), $128 \mu$ (R4) and $45 \mu(\mathrm{R} 2)$; that is, the residual strain of R6 was the largest.

As it has been reported that scaling occurs in the case of freeze-thaw cycle with less than 4 times per day on the temperature range between +20 to $-20{ }^{\circ} \mathrm{C}$ [Tsukinaga et al. 1997], residual strain was large in R12 ( 2 cycles a day) and R6 (4 cycles a day) in this study.

Namely, more daily freeze-thaw cycles per day cannot lead acceleration of frost damage progress and increase in residual strain as an index of frost damage. Actually more daily freeze-thaw cycles lead the higher acceleration of frost damage progress when freezing speed was less than $-20{ }^{\circ} \mathrm{C} /$ hour. Factors affecting the progress of frost damage, such as times of freeze-thaw cycle per day, the lowest temperature and freezing speed are summarized in previous studies [Jacobsen et al. 1997; Koda et al. 2006; Stephan et al. 1997]. It was certainly confirmed that the daily freeze-thaw cycle and freezing speed influence on residual strain during FTC. 


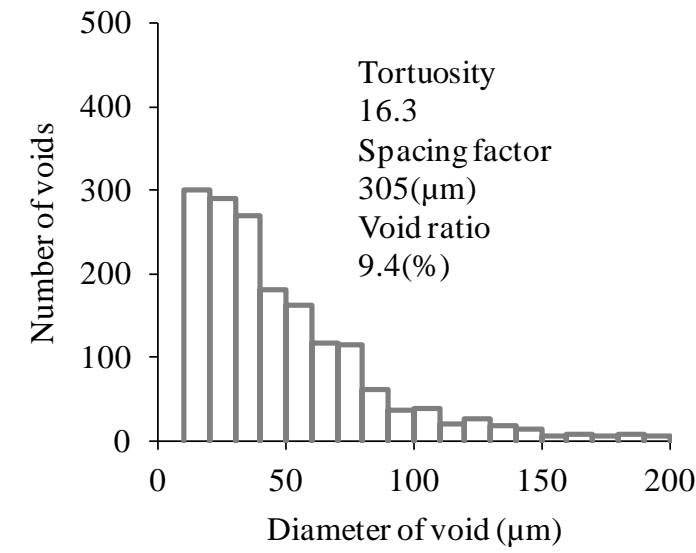

a) R2

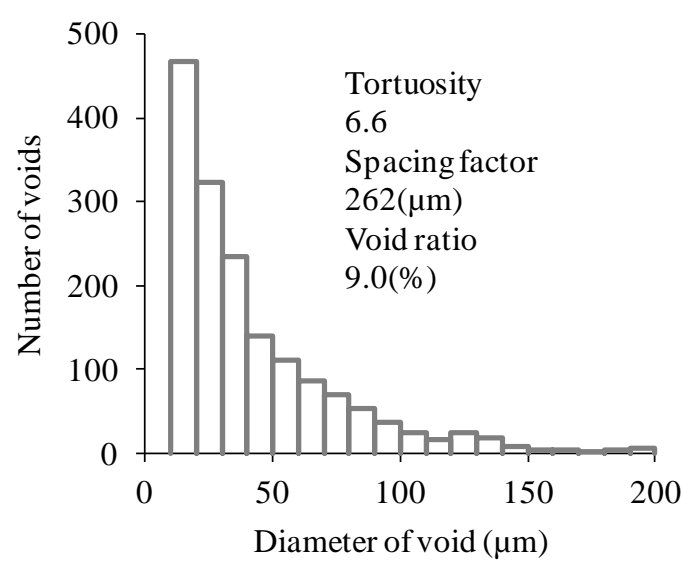

c) R6

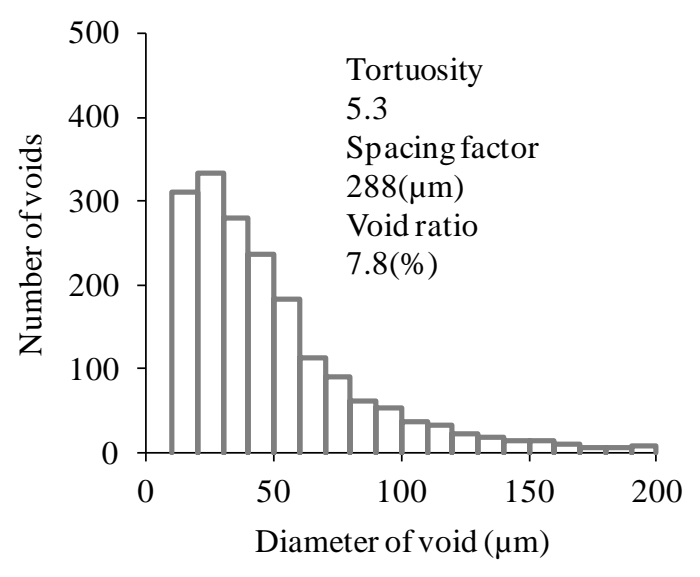

b) R4

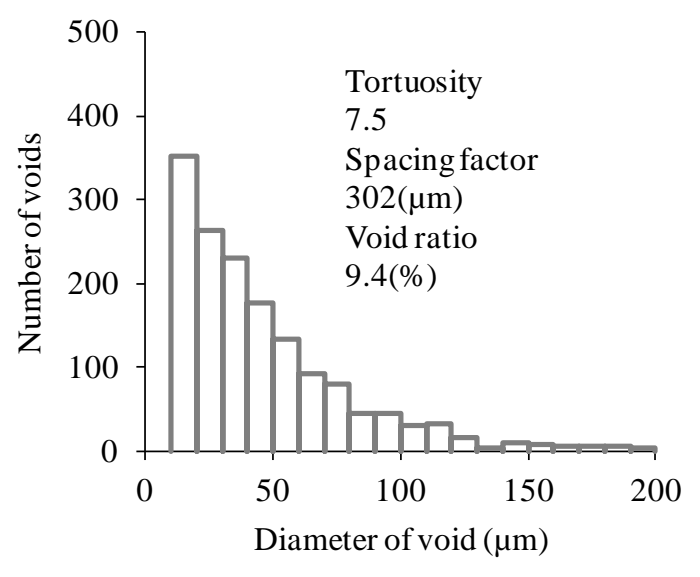

d) R12

\section{Figure 6. Air void distribution (After FTC)}

The total void ratio increased with increase in the freeze-thaw cycles as also shown in Figure 4. It is considered that the pore structure would be changed due to frost damage, although the temperature history did not affect the increase in the total void ratio in this study.

Void distribution and tortuosity. Figures 5 and 6 show 3D air void distributions with the tortuosity and the spacing factor obtained by X-ray CT. Tortuosity and spacing factor from respective data are also shown in the figures. The influence of temperature changes in tortuosity is unclear, although R12, R6, and R4 marked smaller tortuosity and R6 marked the smallest spacing facto; that is, this results indicate that the distance between neighboring pores and space inflection of the cement matrix decreases under a certain freeze-thaw condition as follows: when the temperature history of R4, R6, and R12 compared with that of R2, especially R6 and R12 reduced the tortuosity after FTC. Also, R6 reduced spacing factor the most. This result that R6 was the most effective to occur the physical alteration was similarly observed in that of residual strain as well. 


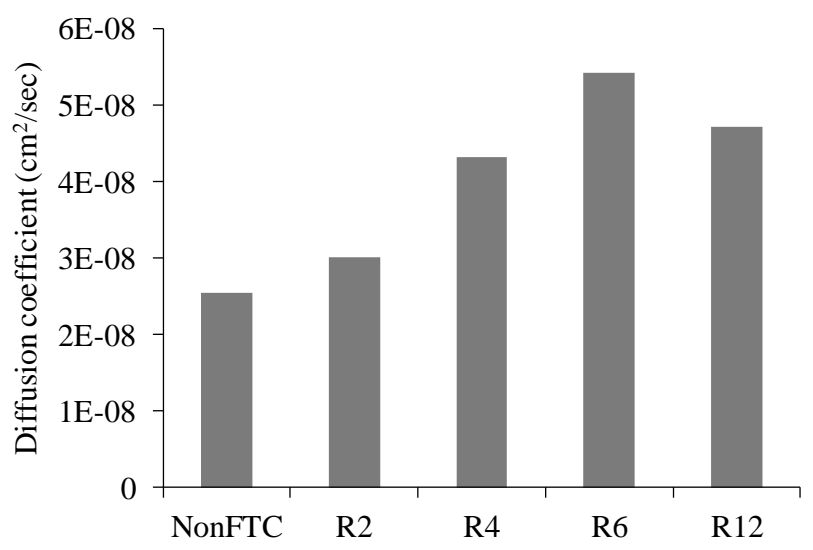

Figure 7. Effective diffusion coefficient

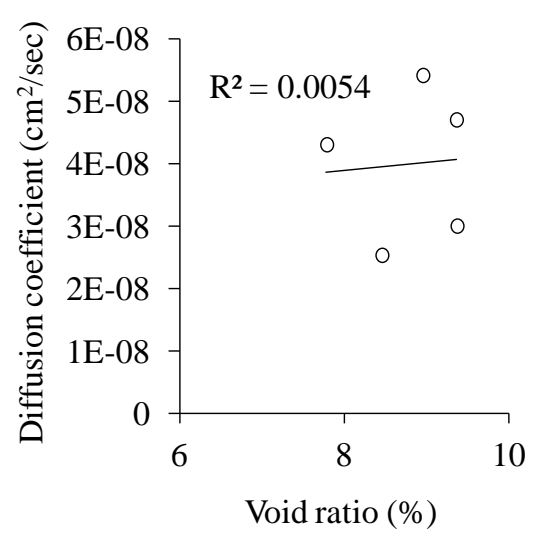

a) Void ratio vs $D_{\mathrm{Cl}}$

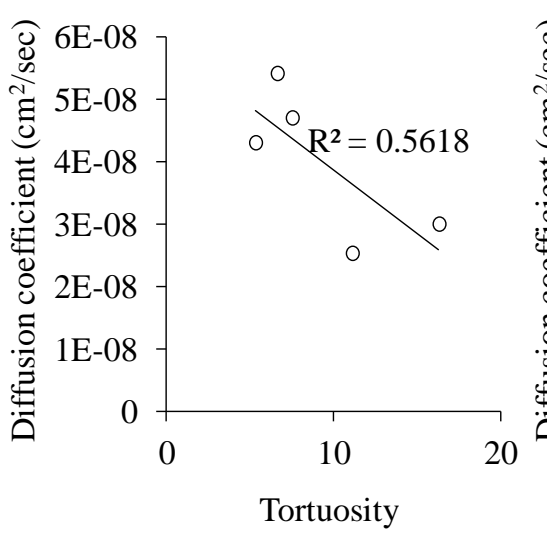

b) Tortuosity vs $D_{\mathrm{Cl}}$

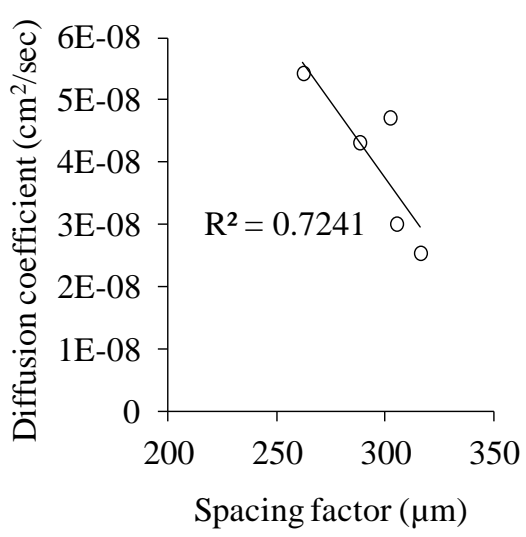

c) Spacing factor vs $D_{\mathrm{Cl}}$

Figure 8. Parameters by X-ray CT analysis on diffusion coefficient of chloride ion

As the results, based on information on 3D air void distribution given by X-ray CT, it is confirmed that the spacing factor and calculated tortuosity in RWS (Random Walk Simulation) can quantitatively evaluate the pore structure as cement matrix property. The X-ray CT analysis in this paper identified that detection and evaluation on air voids with the sizes approximately more than $10 \mu \mathrm{m}$, in cement hardened matrix influenced on increase of pore connectivity with decrease in the spacing factor and tortuosity.

However, although it is estimated that increase in pore connectivity with decrease in the spacing factor and tortuosity occurred due to the development of existing pore or by cracks formation, it is undefined if which phenomenon is dominant within this paper. That is one of future work to understand the fracture mechanism due to frost damage. Moreover, it is needed to investigate if X-ray CT can separate development of existing pores and cracks formation.

Effective diffusion coefficient of chloride ion. Figure 7 shows the effective diffusion coefficient of chloride ion obtained from the minute diffusion test. After FTC at any temperature history, the diffusion 
coefficient was increased. Especially, R6 was the largest followed by R12, R4 and R2. This result corresponds with the residual strains $(491 \mu$ (R6), $364 \mu$ (R12), $128 \mu$ (R4) and $45 \mu$ (R2)). It is widely understood that change in the pore structure leads the physical alteration which is related to the material performance. Using the results of X-ray CT and MIP analysis, it is discussed in the following section of this paper on the relationship between geometrical information of pore structure including pore connectivity and permeability (effective diffusion coefficient). Figure 8 shows the correlations of the data from X-ray $\mathrm{CT}$ with chloride ion diffusion coefficient $\left(D_{\mathrm{Cl}}\right)$.

Alteration of permeability and geometrical information of pore structure due to frost damage. Figure 8 a) shows $D_{\mathrm{Cl}}$ with the total void ratio, which does not show a good correlation. It is concluded that mass transfer and ion permeability do not depend on only absolute pore volume but also pore space property as a connective path. Figure $8 \mathrm{~b}$ ) shows $D_{\mathrm{Cl}}$ with tortuosity, which shows a good correlation. It can be confirmed that $D_{\mathrm{Cl}}$ almost linearly increases with increase of tortuosity. It is concluded that crack propagation due to frost damage increases the connectivity of pore and causes reduction of permeability with tortuosity reduction. Figure $8 \mathrm{c}$ ) shows $D_{\mathrm{Cl}}$ with the spacing factor of air voids, which shows a good correlation on increase of $D_{\mathrm{Cl}}$ with decrease of spacing factor. Similarly with the former result with tortuosity, it is concluded that crack propagation due to frost damage increases the connectivity of pore and causes reduction of permeability with spacing factor reduction. Tortuosity and spacing factor given by the analysis using X-ray CT in this study potentially show pore connectivity approximately more than $10 \mu \mathrm{m}$, a parameter indicating the significant property of pore structure, and the results show that it correlates with the permeability of cement matrix.

\section{CONCLUSION}

This study aimed to clarify physical alteration, such as pore structure and permeability, on frost damage deterioration mechanism based on freeze-thaw cycles with various temperature histories. As the results, tortuosity and pore spacing factor of information from 3D air void distribution by X-ray CT was able to describe and evaluate the permeability with pore connectivity and characteristics in addition to change the absolute pore volume after frost damage.

\section{REFERENCES}

ASTM C 33. "Standard Specification for Concrete Aggregates." ASTM International, West Conshohocken, PA, 11 pages.

Bishnoi, S. (2008). "Strain-temperature hysteresis in concrete under cyclic freeze-thaw conditions." Cement and Concrete Composites, 30(5), 374-380.

Hashimoto, K., Otsuki, N., Saito, T., and Yokota, H. (2013). "Application of Electrical Treatment to Alteration of Cementitious Material due to Leaching." Advanced Concrete Technology, 11, 108-118.

Hashimoto, K., Otsuki, N., Saito, T. and Yokota, H. (2010). "Evaluation of Continuous Pore Structure and Diffusion Coefficient of Cementitious Materials." Proceedings of the 2nd International Conference on Durability of Concrete Structures, Sapporo, Japan, 69-78.

Hisada, M. and Matsuya, R. (2003). "A study on the chemical and physical degradation of hardened cement due to acid rain condition, Journal of Materials." Concrete Structures and Pavements, No.746/V-61, 197-204.

Jacobsen, S. and Sellevold, J., E. (1997). "Frost testing of high strength concrete: Frost/Salt Scaling at Different Cooling Rates." Material and Structures, 30, 33-42. 
Koda, Y., Shoya, M. and Tsukinaga, Y. (2006). “An Experimental Study on Influence of Temperature changes in Freeze-thaw Cycles at Scaling Resistance of Concrete with Deicing Salt. " Cement and Concrete Technology, 59, 278-284.

Mu, R., Miao, C., Luo, X, and Sun, W. (2002). "Combined deterioration of concrete subjected to loading, freeze - thaw cycles and chloride salt attack." Magazine of Concrete Research, 54(3), 175-180.

Nakashima, Y. and Kamiya, S. (2007) "Mathematical programs for the analysis of three dimensional pore connectivity and anisotropic tortuosity of porous rocks using X-ray microtomography." Journal of Nuclear Science and Technology, 44(9), 1233-1247.

Ohta, T., Ohhashi, T., Nemoto, T. and Konagai, N. (1986). "Measurement of air void parameters in hardend concrete using automatic image analyzing system." Proceedings of JCI, Vol.8, 389-392.

Otsuki, N., Wanchai, Y., Nishida, T. and Yamane, H. (2004). "New Test Methods for Measuring Strength and Chloride Ion Diffusion Coefficient of Minute Region in Concrete." ACI Materials Journal, 101(2), 146-153.

Promentilla, M.A.B., Sugiyama, T., Hitomi, T. and Takeda, N. (2008). "Characterizing the 3D Pore Structure of Hardened Cement Paste with Synchrotron Microtomography." Journal of Advanced Concrete Technology, 6(2), 273-286.

Promentilla, M.A.B., Sugiyama, T., Hitomi, T. and Takeda, N. (2009). "Quantification of tortuosity in hardened cement pastes using synchrotron-based X-ray computed microtomograpy." Cement and Concrete Research, 39, 548-557.

Stauffer, D. and Aharony, A. (1994). "Introduction to percolation theory", Revised 2nd Edition - Taylor and Francis, London.

Stephan, J. and Erik, J.S. (1997). "Frost testing of high strength concrete: Frost/Salt Scaling at Different Cooling Rates." Material and Structures, 30, 33-42.

Tsukinaga, Y., Shoya, M., Hara, T. and Otsuka, K. (1997). "Scaling Resistance of Concrete by Automatic Temperature Control Method." Special Publications of the American Concrete Institute, SP-170, Vol.2, pp.1511-1526. 